\title{
The underweight/overweight household: an exploration of household sociodemographic and dietary factors in China
}

\author{
Colleen Doak ${ }^{1}$, Linda Adair ${ }^{1}$, Margaret Bentley ${ }^{1}$, Zhai Fengying ${ }^{2}$ and Barry Popkin ${ }^{1, *}$ \\ 'Department of Nutrition, University of North Carolina at Chapel Hill, CB \# 8120 University Square, 123 West \\ Franklin Street, Chapel Hill, NC, 27516-3997, USA: ${ }^{2}$ Institute of Nutrition and Food Hygiene, Chinese Academy of \\ Preventive Medicine, Beiijing, People's Republic of China
}

\begin{abstract}
Objective: The goal of this paper is to explore the hypothesis that the nutrition transition is related to households having an underweight and an overweight member simultaneously (under/over households and under/over pairs).

Design: The 1993 China Health and Nutrition Survey (CHNS) was used to test the association between being an under/over household and household characteristics related to the nutrition transition. Sociodemographic and diet patterns were tested for the main age combinations of the under/over pairs.

Setting: In China, $8.1 \%$ of all households were found to have underweight and overweight members within the same household.

Subjects: Results are from the 1993 China Health and Nutrition Survey and are based on a sample of 13814 persons from 3340 households.

Results: The under/over household was more urban, had a higher income and was more likely to have assets such as a television, a motor vehicle and a washing machine, even after controlling for sociodemographic confounders. The under/over household had a diet that was higher in fat and protein compared with the underweight and normal weight households. There were no significant differences between the under/over and overweight households, with many of the associations near unity. Comparisons of the under/over subgroups by age of the under/over pairs showed some differences by income and occupation, but not for diet.

Conclusions: It is imperative, as more individuals become exposed to the diet and lifestyle patterns of the nutrition transition, to find effective public health programmes that can simultaneously promote a healthy lifestyle, improve diet quality and address both undernutrition and chronic disease.
\end{abstract}

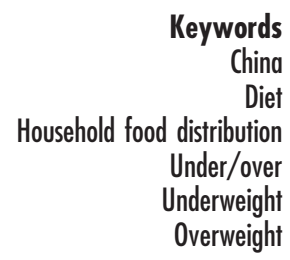

A number of scholars have identified the presence of households with undernutrition and overweight coexisting in the same household. This finding has been regarded as a sign of the shift to the nutrition transition stage linked to diet-related non-communicable disease (NCD). Initial observations in South Africa found low-income, overweight women coexisting in communities with a high prevalence of child undernutrition ${ }^{1,2}$. Subsequent research has shown that this is a common condition in a wide range of countries ${ }^{3-5}$. Garrett and Ruel ${ }^{6}$ have also found obesity and overweight among women clustering with stunting among children. We have hypothesised these findings to be the result of diet and activity changes related to the rapid shift in the stage of the nutrition transition. Here and throughout this paper, the term nutrition transition is used to refer to the shift towards the diet-related NCD phase. Furthermore, emerging and rising obesity in many developing countries ${ }^{7}$ indicate that this might be a broader global concern. However, few studies have considered households with underweight and overweight individuals of any age, simultaneously. These households, which are the focus of this paper, will be henceforth referred to as under/over households, and the underweight and overweight individuals within these households will be referred to as under/over pairs.

The study by Doak et al. ${ }^{5}$ found urban residence to be associated with the under/over households in Brazil, China and Russia. In China, the transitions in diet and activity related to overweight and chronic disease occurred first in the urban areas and among high-income households $^{8-10}$. These factors, as well as other sociodemographic variables such as household assets, may contribute to the likelihood of underweight and overweight clustering within households. The 1993 China Health and Nutrition Survey is used to test the association between household characteristics. Tests were made related to the nutrition transition and being an under/over household. This survey has in-depth anthropometric, dietary and socio-economic status (SES) data from all household members.

It was expected that a common set of factors leads to increased overweight status, which are also related to the 
nutrition transition. These factors include diet, activity, income, assets and urban residence ${ }^{10,11}$. As such, the under/over households are expected to be most like other households with overweight members, even those without underweight persons. On the contrary, households with underweight, but not overweight, individuals are not likely to have household characteristics related to the dietrelated NCD phase of the nutrition transition. These households are expected to be most different from the under/over household in logistic models.

A seven-country study of under/over households found that the dominant pairing was the underweight child together with an overweight adult ${ }^{5}$. However, despite being the most common pair, the under/over pairs with an underweight child and an overweight non-elderly adult explained only 39\% of the under/over households in China $^{5}$. Thus, there are other age combinations of under/over pairs that need consideration. An analysis of the differences between under/over pairs will be undertaken to ascertain if there are distinct sociodemographic and diet patterns related to the age combination of the under/over pair. It is expected that the age combination of the under/over pairs will be related to the household characteristics. It is further expected that not all under/over households will follow the sociodemographic and dietary patterns related to the nutrition transition. Because the transition from undernutrition to overweight occurs first among adults, households with an underweight child and an overweight adult were expected to be most related to the nutrition transition. This study utilises household-level analysis of dietary and other sociodemographic data to more fully explain household differences and specific age combinations related to being an under/over household or pair, respectively.

\section{Data and methods}

\section{The China Health and Nutrition Survey}

Analysis was based on results from the 1993 China Health and Nutrition Survey (CHNS), with 13814 persons from 3340 households. Key variables included: a 3-day average of dietary intake based on three consecutive 24-hour recalls (in combination with household-level weighing) measurement of daily food inventories, and in-depth sociodemographic and anthropometric data ${ }^{12,13}$. The CHNS was chosen because it is a large national survey covering eight provinces, including Guangxi, Jiangsu, Liaoning, Shangdong, Guizhou, Henan, Hubei and Hunan. In addition to having such a large survey, China has been characterised as a country experiencing a rapid transition in diet and activity. Surveys have shown increased consumption of fat and animal protein to be related to shifts in body mass ${ }^{8-12,14-20}$. This research was reviewed and approved by the institutional review board of the University of North Carolina-Chapel Hill (UNC-CH) School of Public Health. The review board at UNC-CH and the Chinese Academy of Preventive Medicine (CAPM) also reviewed and approved procedures for data collection of the CHNS survey.

\section{Classifications of overweight and underweight}

This analysis focuses on measures of current nutrition status; hence we ignored stunting. The weight-for-height status of individuals within a household is the basis of the household classification.

\section{Adults}

Internationally accepted adult body mass index (BMI) cutoffs are well established and were used to define overweight as BMI $\geq 25 \mathrm{~kg} \mathrm{~m}^{-2}$ for adults, 18 years and over. Underweight or chronic energy deficiency ${ }^{10}$ was based on a BMI $<18.5 \mathrm{~kg} \mathrm{~m}^{-2}$.

\section{Children and adolescents}

The choice of an appropriate reference population for Chinese children is problematic because there is no existing reference that reflects the optimal height and weight for them. Furthermore, it is difficult to find a reference sample that is appropriate both for underweight and overweight. We chose to use the International Obesity Task Force (IOTF) BMI references, which are based on an international reference of children 6-18 years of age from six countries ${ }^{21}$. The IOTF cut-offs provide centile equivalents to the adult BMI of 18.5 and $25 \mathrm{~kg} \mathrm{~m}^{-2}$ for each of the six national surveys. These were averaged to obtain an appropriate centile cut-point for the entire international sample. Sensitivity/specificity comparisons were also made against the BMI cut-offs from the National Health and Nutrition Examination Survey I (NHANES I). We used the 5 th percentile for underweight and the 85th percentile for overweight, as suggested by the World Health Organization (WHO) ${ }^{22}$ for this comparison. The results for overweight showed $83 \%$ sensitivity but high specificity (99\%), with 98\% sensitivity and 99\% specificity for underweight. When compared against the standard $Z$-score measures for children 2-10 years old, results were similar. However, the purpose of this study is not to determine the children who are most at risk for nutritional deficiency or overweight and obesity. Instead, it is to identify the phenomenon of both heavy and thin individuals clustering within the household. Therefore, we recognise that these measures are not markers for undernutrition or adiposity per se, but can be used to appropriately identify households with individuals from both ends of the body weight spectrum.

\section{Exclusions}

Pregnant women and children under the age of two were excluded from this analysis because of the difficulty in accurately determining appropriate weight classifications. Single-person households did not have the possibility of 
being an under/over household and were therefore dropped from the analysis.

\section{Classifications of the under/over bousebold}

In order to investigate household sociodemographic characteristics and household diet, the under/over household was categorised as any household with one underweight member together with an overweight member, with or without normal weight persons. This household was compared against three other households:

1. the underweight household, which had an underweight person but no overweight individuals;

2. the overweight household, which had an overweight person and no underweight persons; and

3. the normal weight household, which had neither overweight nor underweight individuals.

\section{Age group classifications within the under/over bousebolds}

A careful analysis of the age combinations of underweight and overweight members in the under/over households was based on a breakdown comprising five age groups: (1) child (2-9.9 years), (2) adolescent (10-17.9 years), (3) young adult (18-39.9 years), (4) middle adult (40-59.9 years) and (5) older adult (60 and over). These age groups were chosen to reflect important developmental or lifestage classifications. The four major clusters of under/over pairs were then determined. These clusters were compared separately against all other under/over households for statistically significant differences by household sociodemographic and diet variables.

\section{Control sociodemographic and diet variables}

The key sociodemographic and diet variables tested for all analyses were urban residence, household income, energy level of the occupation of the household head, TV ownership, ownership of a motor vehicle, ownership of a washing machine, household percentage of energy from fat, household percentage of energy from protein and household percentage of energy from carbohydrate. These variables were chosen because they are related to the lifestyle associated with the nutrition transition. Except where the control variable was the main independent variable being tested, all models were controlled for confounding by household size, income, urban residence, and living in the North versus the South.

\section{Statistical comparisons of the under/over bousebold versus the otber bousebold types}

First, the under/over household was compared in a logistic analysis against the underweight household for differences in each of the household sociodemographic and diet variables. Next, the same analysis was done comparing the under/over household against the overweight household. Finally, the under/over household was compared, by these same sociodemographic and diet variables, to the normal weight household. These statistical comparisons of the under/over to each of the three other household types were made by multiple logistic regression using STATA Corp. statistical software ${ }^{23}$. Logistic comparisons of the under/over household to the underweight, overweight and normal weight households were made separately for each of the main variables.

\section{Statistical comparisons of the main age combinations of the under/over pairs}

Each of the age group combinations was compared to all other under/over households using a simple logistic model. For example, the under child/over adult (an expected main pair) was compared to all other under/over households to test for differences using the same household sociodemographic and diet variables considered above. This analysis was repeated for each age combination of the under/over pairs.

\section{Results}

\section{What factors differentiate the under/over bousebold from other bousebold types?}

In China, $8.1 \%$ of all households were found to have underweight and overweight members within the same household. The sociodemographic and dietary intake characteristics for the main household types are presented in Table 1. In Table 2, the association between urban residence and being an under/over household was 2.0 with a confidence interval (CI) of 1.5 to 2.8 , controlling for income, northern residence and household size. High income was also significantly associated with being an under/over household, with an odds ratio (OR) of 1.7 and a CI of 1.2 to 2.4, controlling for urban residence, northern residence and household size. However, among lowincome households the urban association was 3.1 (CI = $1.7,5.6)$. In comparison, within the middle- and highincome households the urban associations were, respectively, $1.7(\mathrm{CI}=1.02,3.0)$ and $1.8(\mathrm{CI}=1.2$, 3.0). This result, with a higher association of urban residence among low-income households, indicates an interaction between income and urban interaction. This interaction was also found in logistic models with the overweight and normal weight households used as reference.

Table 2 shows the association between being an under/over household and each of the sociodemographic variables. Each OR shown is the result of a separate model, each controlling for income, urban residence, northern residence and household size. The models for household assets, occupation and diet variables included an income and urban interaction term. Owning a television, motor vehicle or washing machine, having a household head with a high-energy occupation, having a household diet with a higher percentage of energy from fat or having a household diet with a higher percentage of energy from 
Table 1 Sociodemographic characteristics and household diet of the four household types

\begin{tabular}{|c|c|c|c|c|}
\hline & Total under/over & $\begin{array}{l}\text { Underweight } \\
\text { household }\end{array}$ & $\begin{array}{l}\text { Overweight } \\
\text { household }\end{array}$ & $\begin{array}{c}\text { Normal } \\
\text { weight } \\
\text { household }\end{array}$ \\
\hline Sample size $(n)$ & 278 & 923 & 883 & 1256 \\
\hline Urban residence (\%) & 39.6 & 24.5 & 40.5 & 26.0 \\
\hline Region: north (\%) & 36.3 & 21.5 & 50.9 & 37.3 \\
\hline Region: south (\%) & 63.7 & 78.6 & 49.2 & 62.7 \\
\hline Real per capita income (Yuan) & 779 & 683 & 824 & 729 \\
\hline Low income (\%) & 31.3 & 36.5 & 30.3 & 33.6 \\
\hline High income (\%) & 37.8 & 27.2 & 40.3 & 31.9 \\
\hline TV ownership (\%) & 88.5 & 75.0 & 89.2 & 77.5 \\
\hline Motor vehicle ownership (\%) & 10.1 & 4.6 & 5.9 & 4.2 \\
\hline Washing machine ownership (\%) & 53.6 & 30.3 & 49.8 & 33.9 \\
\hline Household head has low-energy occupation (\%) & 21.4 & 11.8 & 24.9 & 15.1 \\
\hline Household head has high-energy occupation (\%) & 68.4 & 80.1 & 66.2 & 77.5 \\
\hline Mean carbohydrate (\%) & 61.7 & 64.4 & 61.3 & 63.3 \\
\hline Mean protein (\%) & 12.6 & 12.0 & 12.7 & 12.1 \\
\hline Mean fat (\%) & 25.3 & 23.0 & 25.6 & 24.0 \\
\hline
\end{tabular}

carbohydrate were all significantly associated with being an under/over household when compared with the underweight household. When the under/over households were compared with overweight households, the sociodemographic and diet variables were not significantly different, with ORs near unity and CI intervals crossing unity. Under/over households were more likely to own a television, more likely to have a motor vehicle, more likely to own a washing machine, more likely to consume a higher percentage of energy from fat and protein and less likely to consume a higher percentage of energy from carbohydrate than the normal weight households.

\section{What factors differentiate the age combinations of the under/over pairs?}

However, do the under/over households differ from each other by the age combination of the under/over pairs? In order to answer this question, we focus on four main combinations:

1. an underweight child paired with an overweight young adult (under child/over adult);
2. an underweight adolescent paired with an overweight young or middle adult (under adolescent/over adult);

3. an underweight young adult paired with an overweight child (under young adult/over child); and

4. an underweight young adult paired with an overweight middle adult (under adult/over adult).

These were the most important combinations for the single under/over pair households, and they were also the most important when the multiple pair households were considered separately. Despite these being the most common pairs, these four pair types still account for only $60 \%$ of the under/over households. Analysis on further subgroups would have resulted in very small sample sizes.

Table 3 shows the household means for sociodemographic and diet variables for each of the age combinations of the under/over pairs. Unfortunately, owing to the small sample sizes, only the under/over households with an underweight and overweight adult showed significant results. Households with an underweight young adult together with an overweight middle adult were significantly more likely to be high-income than other under/over households. Even after adjusting for

Table 2 Logistic comparisons of the under/over household versus the underweight, overweight and normal weight households

\begin{tabular}{|c|c|c|c|}
\hline & $\begin{array}{l}\text { Under/over vs. underweight } \\
\text { household }\end{array}$ & $\begin{array}{c}\text { Under/over vs. overweight } \\
\text { household }\end{array}$ & $\begin{array}{l}\text { Under/over vs. normal } \\
\text { weight household }\end{array}$ \\
\hline Urban residence $^{\mathrm{a}}$ & $2.0(1.5,2.8)^{\star \star * *}$ & $1.1(0.8,1.4)$ & $2.2(1.6,2.9)^{\star \star \star *}$ \\
\hline High income $\mathrm{b}^{\mathrm{b}}$ & $1.7(1.2,2.4)^{\star \star \star}$ & $1.0(0.72,1.5)$ & $1.4(0.99,2.0)$ \\
\hline TV ownership ${ }^{c}$ & $1.7(1.1,2.6)^{*}$ & $0.90(0.57,1.4)$ & $1.5(1.02,2.4)^{*}$ \\
\hline Motor vehicle ownership ${ }^{c}$ & $1.8(1.1,3.0)^{*}$ & $1.6(0.94,2.6)$ & $1.8(1.1,2.9)^{\star}$ \\
\hline Washing machine ownership ${ }^{c}$ & $2.0(1.5,2.8)^{\star * \star *}$ & $1.2(0.86,1.6)$ & $1.8(1.3,2.4)^{\star \star \star \star}$ \\
\hline Household head has low-energy occupation ${ }^{c}$ & $1.6(1.1,2,4)^{*}$ & $1.1(0.71,1.6)$ & $1.5(0.99,2.1)$ \\
\hline Mean carbohydrate ${ }^{\mathrm{C}}(\%)$ & $0.98(0.97,0.99)^{\star \star \star}$ & $0.99(0.98,1.01)$ & $0.98(0.96,0.99)^{\star *}$ \\
\hline Mean protein ${ }^{c}(\%)$ & $1.06(0.99,1.1)$ & $0.98(0.92,1.04)$ & $1.06(1.0008,1.1)^{*}$ \\
\hline Mean fat ${ }^{\mathrm{C}}(\%)$ & $1.02(1.0004,1.04)^{\star *}$ & $1.0(0.99,1.02)$ & $1.01(1.003,1.03)$ \\
\hline
\end{tabular}

${ }^{\text {a }}$ Model controlling for income, northern residence and household size.

${ }^{\mathrm{b}}$ Model controlling for urban residence, northern residence and household size.

${ }^{c}$ Model controlling for income, urban residence, income and urban residence interaction term, northern residence and household size.

${ }^{\star}$, Significant at the $P<0.05$ level; ${ }^{* *}$, significant at the $P<0.01$ level; ${ }^{* \star *}$, significant at the $P<0.005$ level; ${ }^{* \star \star *}$, significant at the $P<0.001$ level. 
Table 3 Sociodemographic characteristics and household diet of the four household types

\begin{tabular}{|c|c|c|c|c|c|}
\hline & \multirow[b]{2}{*}{$\begin{array}{c}\text { Adult under/over } \\
\text { household }\end{array}$} & \multicolumn{4}{|c|}{ Subcategories under/over } \\
\hline & & $\begin{array}{l}\text { Child /young } \\
\text { adult }\end{array}$ & $\begin{array}{l}\text { Adolescent/ } \\
\text { adult }\end{array}$ & $\begin{array}{l}\text { Young } \\
\text { adult /child }\end{array}$ & $\begin{array}{l}\text { Young adult/ } \\
\text { older adult }\end{array}$ \\
\hline Sample size $(n)$ & 278 & 40 & 65 & 22 & 47 \\
\hline Urban residence (\%) & 39.6 & 45.0 & 43.1 & 27.3 & 48.9 \\
\hline Region: north (\%) & 36.3 & 42.5 & 35.4 & 31.8 & 36.2 \\
\hline Region: south (\%) & 63.7 & 57.5 & 35.6 & 68.2 & 36.4 \\
\hline Real per capita income (Yuan) & 779 & 611 & 727 & 557 & 915 \\
\hline Low income $(\%)$ & 31.3 & 37.5 & 30.8 & 45.5 & 19.2 \\
\hline High income (\%) & 37.8 & 25.0 & 38.5 & 27.3 & 51.1 \\
\hline TV ownership (\%) & 88.5 & 92.5 & 93.9 & 77.3 & 95.7 \\
\hline Motor vehicle ownership (\%) & 10.1 & 15.0 & 13.9 & 13.6 & 6.4 \\
\hline Washing machine ownership (\%) & 53.6 & 50.0 & 56.9 & 45.5 & 63.8 \\
\hline Household head has low-energy occupation (\%) & 21.4 & 13.9 & 21.7 & 10 & 48.6 \\
\hline Household head has high-energy occupation (\%) & 68.4 & 75.0 & 58.3 & 90 & 45.7 \\
\hline Mean carbohydrate (\%) & 61.7 & 62.9 & 61.7 & 58.7 & 59.6 \\
\hline Mean protein (\%) & 12.6 & 12.4 & 12.8 & 12.9 & 13.0 \\
\hline Mean fat (\%) & 25.3 & 24.3 & 25.5 & 28.5 & 26.6 \\
\hline
\end{tabular}

confounding by urban residence, living in the northern region and household size, this association remained significant $(\mathrm{OR}=2.4 ; \mathrm{CI}=1.01,5.5)$. Otherwise, only one crude OR from the underweight adult/overweight child subgroup was statistically significant. These households were $4.5(\mathrm{CI}=1.03,20.2)$ times more likely to have a household head with a high-energy occupation. These results were attenuated and not statistically significant after controlling for confounders and the urban-income interaction $(\mathrm{OR}=3.1 ; \mathrm{CI}=0.66,14.2)$.

\section{Discussion/conclusion}

\section{Does the under/over bousebold bave sociodemographic characteristics and a bousebold diet consistent with the rapid shift in the stage of the nutrition transition?}

In China, as in many countries experiencing rapid changes in diet and activity, the rates of overweight and obesity increased first among adults $9,17,24$. Often these changes occur despite persistent undernutrition among children. The age group differences in obesity trends led to the hypothesis that clustering within households may occur as a result of an accelerated nutrition transition, such as that experienced in China. At the national level, overweight and obesity have been associated with labour-saving household goods, television ownership, greater reliance on motor vehicle use, and a shift in the occupation structure from high- to low-energy occupations s $^{17,20,25-28}$ The results from sociodemographic comparisons (Tables 1 and 2) show the under/over household to be more likely than the underweight household to own assets that are associated with the nutrition transition. Furthermore, when all under/over households are compared with underweight households, they are significantly more likely to have a household head with a low-energy occupation. The comparison of the under/over and underweight households also showed the under/over household to more likely be urban, and more likely to be high-income. This result was expected, based on previous findings that the nutrition transition begins in urban areas and affects high-income households first.

The income-urban interaction further supports the nutrition transition hypothesis. The comparison between low-income households in urban areas to rural areas is expected to show the strongest contrast in diet and activity lifestyles. This was verified, as represented by the higher odds ratio associated with urban residence among lowincome versus high- and middle-income households. In addition to the interactions of income and urban residence, the under/over household was least different from the overweight household according to sociodemographic and household diet variables. This further supports the hypothesis that the under/over household is driven by factors related to the nutrition transition.

More specific to the nutrition transition was the finding that the under/over household had a diet reflecting the nutrition transition diet. Under/over households had a higher percentage of energy from fat and a lower percentage of energy from carbohydrate when compared with the underweight and normal weight households. Although the statistically significant ORs for the diet results in Table 2 may appear small, these ORs represent the risk associated with a one unit increase in percentage of energy from carbohydrate, fat and protein.

\section{Are there important differences in sociodemographic characteristics and diet differences according to the age combination of the under/over pairs?}

The exploration of sociodemographic and dietary differences by age group combination of the under/over household showed few significant results. The underweight child/overweight adult household may represent 
what has been referred to as the 'little emperor' phenomenon (i.e. representing the spoiled only-child described by the press and others) ${ }^{15,29-33}$. This household may be specific to China, but may also occur in other cultures facing rapid declines in fertility. This household was more likely than other under/over households to have an adult with a high-energy occupation. Although controlling for confounders and effect modification attenuated the effect and reduced statistical significance, the finding is indicative of the need for further research on this phenomenon in China.

The second age group with statistically significant results was the underweight adult/overweight adult. This group was significantly more likely than other under/over households to have a high household income. Despite the small sample size, this finding was true even after controlling for confounders. A secondary analysis of gender showed that, in these households, there were more underweight females than males and also more overweight females than males. Further studies are needed to better understand intergenerational differences in body image, and whether the ideal of an ultra-thin body weight has influenced high-income Chinese women.

\section{What are the public bealth implications of these results?}

The findings of this analysis show the potential role the nutrition transition may have in the clustering of underweight and overweight together. The finding that the under/over household is more likely to occur among highincome and urban households supports the nutrition transition hypothesis. The possibility that a diet with a higher percentage of energy from fat might contribute to the under/over clustering needs to be explored at the individual level, within these households. As the chronic disease phase of the nutrition transition progresses in China, it is imperative that effective public health preventions are found that can simultaneously promote a healthy lifestyle and improve diet quality while addressing both undernutrition and chronic disease.

\section{Acknowledgements}

Financial assistance for this research has come from the US National Institutes of Health (NIH) (R01-HD30880 and R01-HD38700). We thank Cathy Cross for her help with the computer programming, Frances Dancy for administrative support, Tom Swasey for help with the graphics and June Stevens for her helpful comments.

\section{References}

1 Bourne LT, Langenhoven ML, Steyn K, Jooste PL, Laubscher JA, Bourne DE. Nutritional status of 3-6 year-old African children in the Cape Peninsula. East Afr. Med. J. 1994; 71(11): 695-702.

2 Steyn K, Bourne L, Jooste P, Fourie JM, Rossouw K, Lombard
C. Anthropometric profile of a black population of the Cape Peninsula in South Africa. East Afr. Med. J. 1998; 75: 35-40.

3 Doak C, Monteiro C, Popkin BM. The coexistence of obesity and undernutrition in the same households is an emerging phenomenon in lower income countries. Faseb J. 1999; 13(5): A892 [abstract \# 673.2].

4 Doak C, Monteiro C, Popkin BM. Co-existing overweight and underweight within households is related to the nutrition transition. Faseb J. 2000; 14(4): A792 [abstract \# 556.8].

5 Doak CM, Adair LS, Monteiro C, Popkin BM. Overweight and underweight coexist within households in Brazil, China and Russia. J. Nutr. 2000; 130(12): 2965-71.

6 Garrett JL, Ruel M. Stunted child-overweight mother pairs: an emerging policy concern? In: 17th International Congress of Nutrition [special issue]. Ann. Nutr. Metab. 2001; 45(Suppl. 1), 404.

7 Delpeuch F, Maire B. Obesity and developing countries of the south. Medecine Tropicale 1997; 57(4): 380-8 [in French].

8 Paeratakul S, Popkin B, Keyou G, Adair L, Stevens J. Changes in diet and physical activity affect the body mass index of Chinese adults. Int. J. Obes. 1998; 22: 424-31.

9 Popkin BM, Paeratakul S, Zhai F, Ge K. Dietary and environmental correlates of obesity in a population study in China. Obes. Res. 1995; 3(Suppl. 2): 135s-43s.

10 Popkin BM, Keyou G, Zhai F, Guo X, Ma H, Zohoori N. The nutrition transition in China: a cross-sectional analysis. Eur. J. Clin. Nutr. 1993; 47(5): 333-46.

11 Popkin BM. The nutrition transition in low-income countries: an emerging crisis. Nutr. Rev. 1994; 52: 285-98.

12 Popkin B, Bing L, Zhai F. Understanding the nutrition transition: measuring rapid dietary changes in transitional countries. Public Health Nutr. 2001 [in press].

13 Zhai F, Guo X, Popkin BM, Ma L, Wang Q, Yu W, et al. The evaluation of the 24-hour individual recall method in China. Food Nutr. Bull. 1996; 17: 154-61.

14 Wang Y, Popkin B, Zhai F. The nutritional status and dietary pattern of Chinese adolescents, 1991 and 1993. Eur. J. Clin. Nutr. 1998; 52(12): 908-16.

15 Du S, Lu B, Zhai F, Popkin BM. A new stage of the nutrition transition in China. Public Health Nutr. 2002; 5: 169-74.

16 Popkin BM, Paeratakul S, Zhai F, Ge K. A review of dietary and environmental correlates of obesity with emphasis on developing countries. Obes. Res. 1995; 3(Suppl. 2): $145 \mathrm{~s}-53 \mathrm{~s}$.

17 Popkin BM, Paeratakul S, Ge K, Fenying Z. Body weight patterns among the Chinese: results from the 1989 and 1991 China Health and Nutrition Surveys. Am. J. Public Health 1995; 85(5): 690-4.

18 Guo X, Popkin BM, Mroz TA, Zhai F. Food price policy can favorably alter macronutrient intake in China. J. Nutr. 1999; 129(5): 994-1001.

19 Ge K, Weisell R, Guo X, Cheng L, Ma H, Zhai F, et al. The body mass index of Chinese adults in the 1980s. Eur.J. Clin. Nutr. 1994; 48: S148-54.

20 Drewnowski A, Popkin BM. The nutrition transition: new trends in the global diet. Nutr. Rev. 1997; 55(2): 31-43.

21 Cole TJ, Bellizzi MC, Flegal KM, Dietz WH. Body mass index in children worldwide: cut-off points for underweight, overweight and obesity. Br. Med. J. 2001; 320(7244): 12403.

22 World Health Organization (WHO). Physical Status: The Use and Interpretation of Anthropometry. Report of a WHO Expert Committee. WHO Technical Report Series No. 854. Geneva: WHO, 1995.

23 STATA Corporation. STATA Version 6.O. College Station, TX. Stata Corporation, 1999.

24 Zhai F, Lu B, Jin S, Popkin BM. Impact of maternal income on the nutrients intake of preschool children - a case study in 8 provinces of China. Wei Sheng Yan Jiu 1998; 27(4): 269-72. 
25 Doak CM, Popkin BM. The emerging problem of obesity in developing countries. In: Semba R, Bloem M, eds. Nutrition and Health in Developing Countries, Totowa, NJ: Humana Press, 447-64.

26 Popkin BM. The nutrition transition and its health implications in lower income countries. Public Health Nutr. 1998; 1: 5-21.

27 Popkin BM, Doak C. The obesity epidemic is a worldwide phenomenon. Nutr. Rev. 1998; 56: 106-14.

28 Popkin BM, Bisgrove EZ. Urbanization and nutrition in lowincome countries. Food Nutr. Bull. 1988; 10(1): 3-23.

29 Chee BWL. Eating snacks and biting pressure: only children in Beijing. In: Jing J, ed. Feeding China's Little Emperors: Food, Children and Social Change. Stanford, CA: Stanford University Press, 2000; 48-70.

30 Yuhua G. Family relations: the generation gap at the table.
In: Jing J, ed. Feeding China's Little Emperors: Food, Children and Social Change. Stanford, CA: Stanford University Press, 2000; 94-113.

31 Watson JL. Food as a lens: the past, present, and future of family life in China. In: Jing J, ed. Feeding China's Little Emperors: Food, Children and Social Change. Stanford, CA: Stanford University Press, 2000; 199-212.

32 Gillette MB. Children's food and Islamic dietary restrictions in Xi'an. In: Jing J, ed. Feeding China's Little Emperors: Food, Children and Social Change. Stanford, CA: Stanford University Press, 2000; 71-93.

33 Jing J. Food, children, and social change in contemporary China. In: Jing J, ed. Feeding China's Little Emperors: Food, Children and Social Change. Stanford, CA: Stanford University Press, 2000; 1-26. 